\title{
EFISIENSI ENERGI UNTUK MEMPERPANJANG LIFETIME JARINGAN SENSOR NIRKABEL MENGGUNAKAN ALGORITMA LEACH
}

\author{
Oktavia A Permata ${ }^{1}$, Khodijah Amiroh ${ }^{2}$, Farah Z Rahmanti ${ }^{3}$ \\ ${ }^{1,2,3}$ Institut Teknologi Telkom Surabaya \\ Email: ${ }^{1}$ oktapermata@ittelkom-sby.ac.id, ${ }^{2}$ dijaamirah@ittelkom-sby.ac.id, ${ }^{3}$ farah.zakiyah@ittelkom-sby.ac.id
}

(Naskah masuk: 6 Maret 2020, diterima untuk diterbitkan: 27 Maret 2020)

\begin{abstract}
Abstrak
Efisiensi energi dalam transmisi dan pengumpulan data menjadi faktor penting dalam jaringan sensor nirkabel (WSN). Efisiensi energi berkaitan erat dengan lifetime jaringan. Aktifitas transmisi data merupakan hal yang membutuhkan energi paling besar pada jaringan WSN. Maka dibutuhkan suatu metode algoritma untuk menyelesaikan permasalahan tersebut. Dalam penelitian ini diusulkan metode yang berbasis algoritma LEACH untuk menentukan cluster head dan mengetahui energi yang tersisa pada masing - masing node. Cluster Head $(\mathrm{CH})$ adalah suatu node pada WSN yang berperan sebagai leader yang akan mengakomodir data bagi seluruh anggota node (SN) dalam suatu jaringan. $\mathrm{CH}$ dipilih berdasarkan jarak. Idealnya $\mathrm{CH}$ memiliki jarak terpendek baik antar SN maupun Base Station (BS). Hal ini karena semakin panjang jarak akan semakin membutuhkan energi yang besar. Pemilihan $\mathrm{CH}$ tidak hanya dari segi jarak tetapi kandidat harus memiliki residual energy yang lebih besar dari rata - rata residual energy node lain. Semakin tinggi residual energi pada $\mathrm{CH}$ nodes, semakin menjamin kelangsungan lalu lintas data menuju base station. Untuk itu node dengan residual energy yang lebih besar memiliki probabilitas yang lebih tinggi untuk dijadikan $\mathrm{CH}$ node. Dalam penelitian ini, hasil dapat dinilai dari seberapa banyak node sensor yang mati, seberapa lama lifetime dari jaringan itu sendiri, total konsumsi energi dari metode routing protocol. Hasil menunjukkan bahwa algoritma LEACH mampu menaikan troughput dari normalnya berkisar $640 \mathrm{~Kb}$ menjadi $1500 \mathrm{~Kb}$ pada round ke 1000. Jumlah node yang mati juga berkurang dan grafik total energi yang normalnya turun drastis menjadi lebih landai. Dengan kata lain algoritma LEACH sangat baik dalam mengoptimisasi lifetime jaringan pada WSN.
\end{abstract}

Kata kunci: pemilihan cluster head, Algoritma LEACH, jaringan sensor nirkabel

\section{ENERGY EFFICIENCY TO PROLONG WIRELESS SENSOR NETWORK LIFETIME USING LEACH ALGORITHM}

\begin{abstract}
Energy efficiency is considered as the important things in wireless sensor network because it is related to the network lifetime. The most energy consumed in wireless sensor network is in data transmission. To reduce the energy consumption we propose a method based LEACH algorithm to determine cluster head and residual energy in each node. Cluster Head $(\mathrm{CH})$ is a node used as a leader which will manage the data transmission for all the cluster member in the network. $\mathrm{CH}$ is selected based on the distance. Ideally $\mathrm{CH}$ has the minimum distance both between cluster member and base station. We choose the minimum distance because the longer the distance the more energy will be consumed. The $\mathrm{CH}$ selection is not only in terms of distance but the candidate must have a residual energy that is greater than the average residual energy of other nodes. Residual energy is related to the flow of data traffic. The higher residual energy the node has, the flow of data traffic to the base station can be done simultaneously. For this reason, nodes with minimum distance and greater residual energy have a higher probability of being $\mathrm{CH}$ nodes. In this research, the results can be shown from the number of dead nodes, the longer of network lifetime, and total energy consumed from routing protocol. The right selection of $\mathrm{CH}$ will affect the performance of wireless sensor network. The more effective the network performance will have a big impact on network lifetime given the limited energy sources.
\end{abstract}

Keywords: cluster head selection, LEACH algorithm, residual energy, wireless sensor network 


\section{PENDAHULUAN}

Jaringan sensor nirkabel atau Wireless Sensor Network (WSN) merupakan suatu jaringan infrastruktur yang terdiri atas sekumpulan sensor node $(\mathrm{SN})$ yang dapat saling berkomunikasi pada suatu area sensor. Sensor node berkomunikasi tidak hanya dengan sesama sensor node tetapi juga dengan base station (BS) atau sink node melalui transmisi gelombang radio, yang memungkinkan mereka menyebarkan data sensor untuk remote processing, visualisasi, analisis, dan storage systems [1]. Masalah pemilihan routing, yaitu mencari lintasan multihop dari sensor node ke base station adalah salah satu tantangan penting dalam WSN [1]. Untuk alasan inilah, perancangan model routing dan protokol transmisi pada WSN yang dapat meningkatkan efisiensi energi dan memperpanjang lifetime dari WSN telah mendapatkan perhatian yang cukup besar dari para peneliti [2].

Diantara beberapa protokol routing yang telah diusulkan dalam WSN, algoritma cluster-based adalah yang lebih efektif dalam memenuhi kebutuhan jaringan sensor nirkabel, terutama dalam hal konsumsi energi. Dengan pengelompokan sensor node ke dalam beberapa kelompok yang disebut cluster, maka sensor node dari setiap cluster mengirim data mereka untuk sensor node tertentu dalam cluster yang disebut Cluster Head $(\mathrm{CH})$. Kemudian, $\mathrm{CH}$ node mentransmisikan informasi yang telah dikumpulkan ke base station. Karena $\mathrm{CH}$ node memainkan peran penting dalam kinerja algoritma routing yang berbasis cluster, maka kebijakan pemilihan $\mathrm{CH}$ node sangat berpengaruh terhadap beberapa parameter jaringan sensor diantaranya yaitu lifetime jaringan dan tingkat konsumsi energi [2]. Gambar 1 menunjukkan gambaran umum dari WSN yang terdiri atas base station, cluster head dan sensor node atau cluster member.

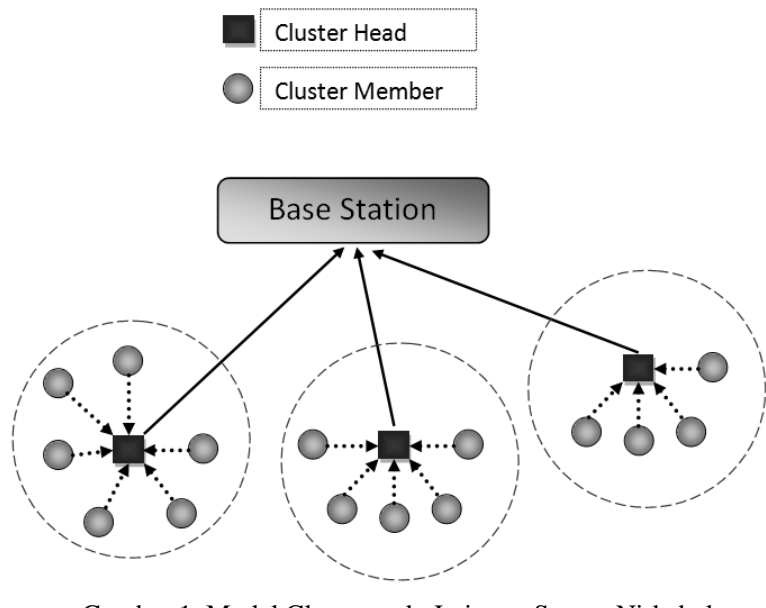

Gambar 1. Model Cluster pada Jaringan Sensor Nirkabel

Terdapat beberapa jenis protokol routing yang biasa digunakan dalam WSN yaitu TEEN, PEGASIS, LEACH, dan lain - lain. LEACH (Low-
Energy Adaptive Clustering Hierarchy) merupakan protokol routing berdasarkan cluster yang paling populer dalam WSN. Algoritma LEACH ini menggunakan suatu model acak untuk memilih $\mathrm{CH}$ node kemudian non- $\mathrm{CH}$ node bergabung dengan cluster melalui transmisi one-hop menggunakan TDMA (Time Division Multiple Access) [2].

Dalam paper ini, diusulkan metode pengembangan algoritma LEACH untuk menentukan cluster head dan mengetahui energi yang tersisa pada masing - masing node. Tiap node menggunakan algoritma stokastik pada tiap round untuk menentukan apakah node tersebut akan menjadi cluster head dalam round tertentu. Node yang telah menjadi cluster head tidak bisa menjadi cluster head lagi pada round $\mathrm{p}$, dimana $\mathrm{p}$ adalah persentase yang diinginkan dari cluster head. Oleh karena itu tiap node memiliki probabilitas $1 / \mathrm{p}$ untuk menjadi cluster head pada tiap round. Dalam algoritma LEACH ini juga menggunakan CDMA sehingga tiap cluster memanfaatkan sekumpulan kode yang berbeda untuk meminimalkan interferensi antar cluster.

\section{METODE PENELITIAN}

Pada penelitian ini, permasalahan bagaimana memperpanjang lifetime jaringan pada WSN dilakukan dengan cara optimisasi pada pemilihan Cluster Head. Maka dibutuhkan metode algoritma untuk menyelesaikan permasalahan tersebut. Adapun metode yang diusulkan adalah algoritma LEACH yang kemudian dalam implementasinya disimulasikan kedalam software MATLAB.

\subsection{Algoritma LEACH}

LEACH memiliki beberapa putaran (round) dengan menyesuaikan jumlah $\mathrm{CH}$ yang diinginkan dan masa observasi. LEACH memastikan tiap node akan menjadi $\mathrm{CH}$ untuk satu round. Akibatnya kedudukan $\mathrm{CH}$ menjadi tidak tetap atau bergantian sehingga suatu cluster memiliki formasi yang dinamis setiap round. Algoritma LEACH dibagi menjadi 2 fase, yaitu fase setup dan fase steady state [3].

Pada fase setup terjadi penentuan $\mathrm{CH}$ dan proses pembentukan cluster atau sering disebut juga dengan algoritma clustering. Sedangkan pada fase steady state, terjadi proses transfer data antar node yang melibatkan aktivitas transmisi dan observasi. Proses steady state memakan waktu yang lebih lama dibandingkan dengan proses setup. Hal ini disebabkan karena transfer data terjadi melalui transmisi radio secara intensif.

\subsection{Pembentukan Cluster}

LEACH memiliki beberapa putaran (round) dengan menyesuaikan jumlah $\mathrm{CH}$ yang diinginkan dan masa observasi. LEACH memastikan tiap node akan menjadi $\mathrm{CH}$ untuk satu round. Akibatnya 
kedudukan $\mathrm{CH}$ menjadi tidak tetap atau bergantian sehingga suatu cluster memiliki formasi yang dinamis setiap round. Algoritma LEACH dibagi menjadi 2 fase, yaitu fase setup dan fase steady state [3]. Pada fase setup terjadi penentuan $\mathrm{CH}$ dan proses pembentukan cluster atau sering disebut juga dengan algoritma clustering. Sedangkan pada fase steady state, terjadi proses transfer data antar node yang melibatkan aktivitas transmisi dan observasi. Proses steady state memakan waktu yang lebih lama dibandingkan dengan proses setup. Hal ini disebabkan karena transfer data terjadi melalui transmisi radio secara intensif.

Awal mula, ketika cluster sedang dibentuk, setiap node memutuskan apakah akan menjadi $\mathrm{CH}$ atau tidak untuk round saat itu. Keputusan ini didasarkan pada persentase yang disarankan dari $\mathrm{CH}$ dan seberapa kali node tersebut telah menjadi $\mathrm{CH}$. Keputusan ini dibuat oleh node $\mathrm{n}$ dengan memilih nomor acak antara 0 dan 1 . Jika jumlah yang dipilih kurang dari threshold $\mathrm{T}(\mathrm{n})$, maka node menjadi $\mathrm{CH}$ untuk round saat itu. Threshold yang ditetapkan adalah sebagai berikut:

$$
\mathbf{T}(\mathbf{n})=\left\{\begin{array}{lr}
\frac{\mathrm{p}}{1-\mathrm{p} \times(r \bmod 1 / \mathrm{p})}, & \text { jika } \mathrm{E} \in \mathrm{G} \\
0, & \text { yang lain }
\end{array}\right.
$$

dimana $\mathrm{p}$ adalah persentase yang diinginkan dari $\mathrm{CH}, \mathrm{r}$ adalah round saat itu, dan $\mathrm{G}$ adalah sekumpulan node yang belum menjadi $\mathrm{CH}$ dalam $1 / \mathrm{p}$ round akhir [4].

Pada algoritma ini, tiap node menjadi $\mathrm{CH}$ kurang lebih sekali dalam $1 / \mathrm{p}$ round. Setelah ((1/p)1) round, $\mathrm{T}(\mathrm{n})=1$ untuk semua node yang belum menjadi $\mathrm{CH}$. Ketika sebuah node telah memilih dirinya sendiri sebagai $\mathrm{CH}$ node, maka dia membroadcast pesan advertisement yang mengatakan kepada semua node bahwa dirinya telah terpilih sebagai $\mathrm{CH}$. Non- $\mathrm{CH}$ node menggunakan pesan dari $\mathrm{CH}$ node untuk memilih cluster yang mereka inginkan untuk berada di dalam round tersebut yang didasarkan pada RSSI (Received Signal Strength Indicator) dari paket advertisement. Tergantung pada jumlah node di dalam cluster, $\mathrm{CH}$ node kemudian membuat jadwal TDMA yang mengatur tiap node ketika akan mentransmisikan paket data. Jadwal ini kemudian dibroadcast ke semua node di dalam cluster [5].

\subsection{Pengiriman paket}

Setelah cluster terbentuk dan jadwal TDMA telah ditetapkan, node - node bisa mulai mengirimkan paket data. Node - node ini mengirimkan data mereka ke $\mathrm{CH}$ masing - masing paling banyak sekali per frame selama slot transmisi alokasi mereka. Asumsi node - node selalu memiliki data untuk dikirim, mereka mengirim data selama waktu transmisi alokasi mereka ke $\mathrm{CH}$. Transmisi ini menggunakan minimum energi berdasarkan kuat sinyal yang diterima dari advertisement $\mathrm{CH}$. Radio dari tiap non- $\mathrm{CH}$ dapat dimatikan hingga waktu transmisi node alokasi selesai, sehingga disipasi energi berkurang. $\mathrm{CH}$ harus menjaga receivernya agar tetap ON untuk menerima semua data dari node di dalam cluster. Setelah semua data diterima, $\mathrm{CH}$ menampilkan fungsi optimasi. Resultan paket data ini kemudian ditransmisikan ke base station. Proses ini berlangsung dalam fase steady state [5].

\subsection{Simulasi Matlab}

Pada penelitian ini algoritma LEACH yang telah diusulkan disimulasikan kedalam software MATLAB. Dibutuhkan beberapa parameter penting untuk mensimulasikan keadaan real suatu lingkungan yang terdapat jaringan WSN. Hal ini dimaksudkan agar usulan metode permasalahan dapat lebih mudah untuk di implementasikan kedalam aplikasi nyata. Adapun parameter penting yang mendukung proses simulasi ditunjukan pada Tabel 1.

\begin{tabular}{ccc}
\multicolumn{3}{c}{ Tabel 1 Parameter Jaringan } \\
\hline Parameter & Simbol & Nilai \\
\hline Area dari SN & M x M & $100 \mathrm{~m} \mathrm{x} \mathrm{100m}$ \\
Jumlah SN & $\mathrm{N}$ & 100 node \\
Lokasi dari BS & $\mathrm{BS}(\mathrm{x}, \mathrm{y})$ & $(50,175)$ \\
Inisial energi node & $\mathrm{E}_{\mathrm{init}}$ & $0.5 \mathrm{~J}$ \\
Prosentase pemilihan CH & $\mathrm{p}$ & 0.1 \\
ETx dan ERx & $\mathrm{E}_{\mathrm{elec}}$ & $50 \mathrm{~nJ} / \mathrm{bit}$ \\
Free space & $\varepsilon_{f s}$ & $10 \mathrm{pJ} / \mathrm{bit} / \mathrm{m}^{2}$ \\
Multipath fading & $\varepsilon_{m p}$ & $0.0013 \mathrm{pJ} / \mathrm{bit} / \mathrm{m}^{2}$ \\
Energi agresi & $\mathrm{E}_{\mathrm{DA}}$ & $5 \mathrm{~nJ} / \mathrm{bit} / \mathrm{signal}$ \\
Ukuran paket data & $\mathrm{Kd}$ & $6400 \mathrm{bit}$ \\
Ukuran paket kontrol & $\mathrm{Kc}$ & $200 \mathrm{t}$ \\
& &
\end{tabular}

\subsection{Pemetaan Area Sensor}

Untuk mesimulasikan kondisi real digunakan 100 node yang terdistribusi secara random pada area sebesar 100x100 meter, dan lokasi BS pada posisi (50,175). Pada Gambar 2 menunjukkan simulasi dari pemetaan area WSN terkait jarak antar SN, jarak SN dengan BS dan lain-lain. Posisi BS diatur supaya berada ditengah - tengah area simulasi. Adapun maksud dan tujuan dari pemetaan ini adalah untuk memodelkan kondisi real suatu lingkungan dimana tersebar sensor node secara acak pada suatu wilayah yang kondisi realnya memiliki luas hingga orde kilometer. Namun dalam penelitian ini untuk menganalisa algoritma LEACH cukup dilakukan dengan mensimulasikan suatu wilayah dengan luas 100 meter $^{2}$ ( $100 \times 100$ meter ). 


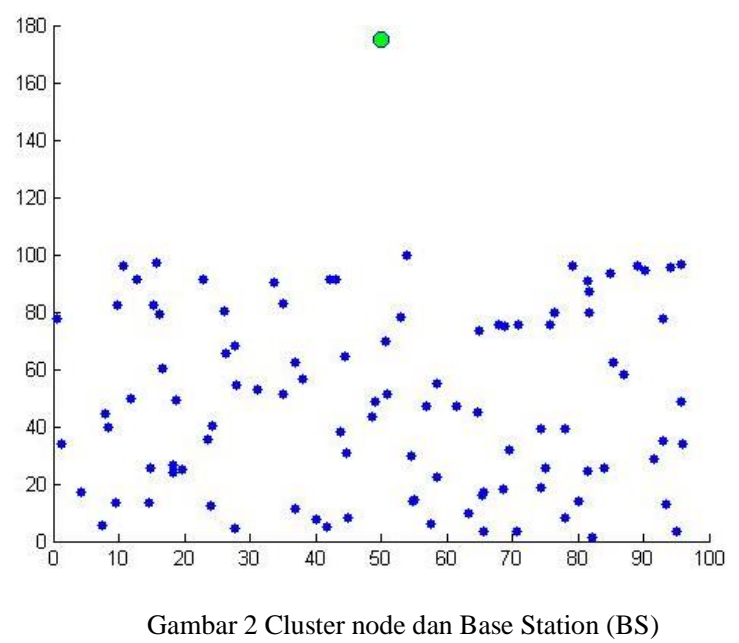

\subsection{Inisialisasi Energi pada Tiap Node}

Semua node memiliki energi inisialisasi yang sama sebesar 0,5 Joule atau 500 mili Joule. Tentunya pada kondisi sebenarnya, tiap sensor memiliki sumber daya yang tersedia dan akan habis bila terjadi aktifitas baik untuk transfer paket data maupun transfer paket kontrol. Adapun aktivitas utama adalah transfer data baik mengirim maupun menerima sebesar 50nJ/bit. Dalam hal ini data bisa berupa paket data yang memiliki size 6400 bit/paket maupun data kontrol yang memiliki size 200bit/paket. Seperti yang terlihat pada Gambar 3. Awal mula $\mathrm{CH}$ member memberi instruksi dengan mengirim bit kontrol pada SN kemudian SN membalas dengan mengirim paket. Kedua step aktifitas ini membutuhkan energi bagi $\mathrm{SN}$ dan $\mathrm{CH}$.

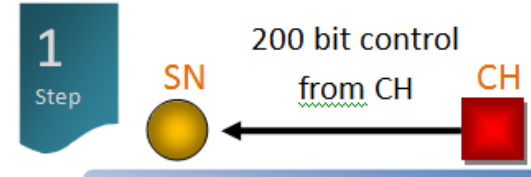

$\mathrm{CH}$ and SN Loss $200 \times 50 \mathrm{~nJ}=10 \mathrm{~mJ}$

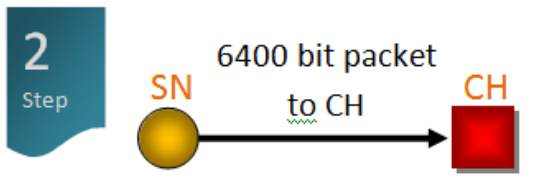

$\mathrm{CH}$ and SN Loss $6400 \times 50 \mathrm{~nJ}=320 \mathrm{~mJ}$

Gambar 3 Ilustrasi dari Transfer Paket Data dan Kontrol antara $\mathrm{SN}$ dan $\mathrm{CH}$

Jika untuk satu kali aktivitas transfer data SN membutuhkan $320+10 \mathrm{~mJ}$, sedangkan inisialisasi awal tiap SN sebesar $500 \mathrm{~mJ}$, ditambah parameter lain yaitu energi agresi sebesar $5 \mathrm{nj} / \mathrm{bit} / \mathrm{sinyal}$, maka node akan cepat mati. Sehingga aspek penting yang dianalisa oleh algoritma LEACH adalah berapa banyak paket yang telah terkirim di base station, jumlah node yang mati dan total energi dari semua node pada saat round terakhir.

\subsection{Proses Komputasi Algoritma LEACH}

Pada proses ini beberapa parameter yang berpengaruh terhadap komputasi adalah probabilitas cluster head (p) adalah 0,1. Dimana output dari komputasi adalah menghasilkan urutan SN yang difungsikan sebagai Cluster Head $(\mathrm{CH})$ pada suatu round. Adapun parameter lain yang berpengaruh terhadap jarak ke base station dan antar anggota SN adalah freespace sebesar $10 \mathrm{pJ} / \mathrm{bit} / \mathrm{m} 2$ dan multipath fading sebesar $0.0013 \mathrm{pJ} / \mathrm{bit} / \mathrm{m} 2$.

\section{HASIL DAN PEMBAHASAN}

Pada penelitian ini, permasalahan optimisasi lifetime pada jaringan WSN disimulasikan kedalam software MATLAB dengan menggunakan algoritma LEACH. Tujuan dari simulasi ini adalah untuk melakukan uji coba pada 3 hal, antara lain:

- Jumlah paket yang terkirim ke BS.

- Jumlah node yang mati.

- Jumlah total energi dari semua node.

Ketiga proses uji coba tersebut dilakukan hingga round akhir. Round akhir dalam hal ini adalah iterasi maksimum yang diinginkan.
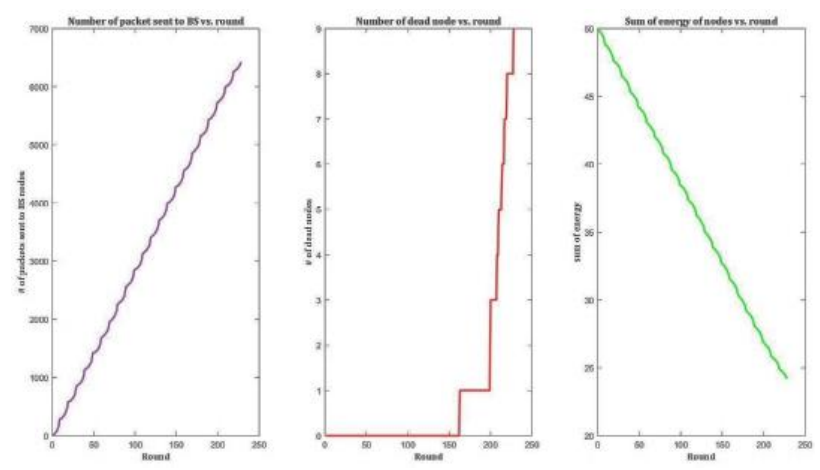

Gambar 4 Hasil simulasi dengan 250 putaran
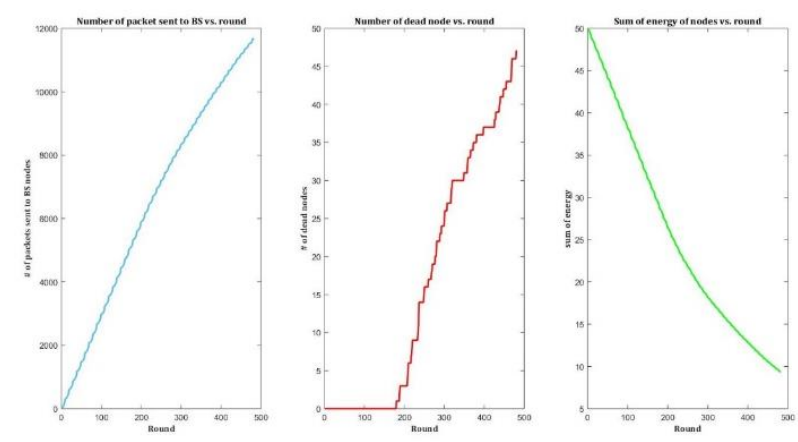

Gambar 5 Hasil simulasi dengan 500 putaran

Dari perbandingan hasil simulasi diketahui bahwa semakin banyak jumlah putaran yang dilakukan maka semakin banyak node yang mati, total jumlah energi juga akan semakin berkurang, tetapi jumlah paket yang terkirim ke BS akan semakin banyak. Dengan demikian menunjukan bahwa algoritma LEACH bekerja dengan baik. Dimana kualitas 
throughput dapat dilihat dari jumlah paket yang diterima oleh BS lebih besar dari paket loss. Kemudian aktivitas transmisi paket data oleh tiap node yang semestinya menguras banyak energi, berhasil ditanggulangi oleh algoritma LEACH. Sehingga dapat menjadikan aktivitas transmisi menjadi lebih efisien dalam pemanfaatan energi yang terkandung pada tiap node. Hal ini menandakan kinerja dari algoritma LEACH dalam memilih $\mathrm{CH}$ yang tepat sudah cukup bagus sehingga total keseluruhan energi pada jaringan WSN tidak turun drastis.

\section{KESIMPULAN DAN SARAN}

Penelitian ini telah dilakukan analisa performa dari algoritma LEACH. Pada dasarnya algoritma melakukan pemilihan node secara random, sehingga peluang dari setiap node adalah sama dan beban dari keseluruhan jaringan menjadi seimbang. Penggunaan algoritma LEACH menunjukan hasil yang positif. Seperti yang didapat dari 3 poin hasil uji coba. Algoritma ini mampu menaikan troughput dari normalnya berkisar $640 \mathrm{~Kb}$ menjadi $1500 \mathrm{~Kb}$ pada round ke 1000 . Selain itu mampu menghambat angka node yang mati dan yang terakhir menghambat grafik total energi yang normalnya turun drastis menjadi lebih landai. Dengan kata lain algoritma LEACH sangat baik dalam mengoptimisasi lifetime jaringan pada WSN.

Performansi LEACH sangatlah luar biasa. Namun, di sisi lain LEACH memiliki beberapa kekurangan misalnya dalam hal skalabilitas dan level residual energy yang sama di setiap node, sehingga perlu dilakukan modifikasi atau teknik pengembangan agar diperoleh hasil yang lebih optimal.

\section{DAFTAR PUSTAKA}

[1] W. Dargie, dan C. Poellabauer, 2010. "Fundamentals of Wireless Sensor Networks", John Wiley \& Sons Ltd, United Kingdom.

[2] T. G. Nguyen, C. So-In, N. G. Nguyen, 2014. "Two Energy-Efficient Cluster Head Selection Techniques Based on Distance for Wireless Sensor Network", IEEE International Computer Science and Engineering Conference (ICSEC).

[3] M, A. Permana, 2008. "Analisa Algoritma LEACH Pada Jaringan Sensor Nirkabel", Proceeding Seminar Tugas AKhir Jurusan Teknik Elektro FTI-ITS, 2008.

[4] W, R. Heinzelman., A. Chandrakasan., dan H. Balakrishnan, 2000. "Energy-Efficient Communication Protocol for Wireless Microsensor Networks", Proceeding of the 33rd Hawaii International Conference on System Sciences.
[5] J. Abdullah dan S. Zeni, 2014. "Maximizing the Network Lifetime of Clustered-Based WSN Using Probability of Residual Energy", IEEE International Conference on Control System, Computing and Engineering, November.

[6] I. Akyildiz, W. Su, Y. Sankarasubramaniam, and E. Cayirci, 2020. "Wireless sensor networks: a survey," Compu. Netw. J., pp. 393-422.

[7] S. Tyagi and N. Kumar, 2013. "A systematic review on clustering and routing techniques based upon LEACH protocol for wireless sensor networks," J. of Netw. and Comput. Appl., vol. 36, no. 2, pp. 623-645

[8] A. Abbasi and M. Younis, 2007. "A survey on clustering algorithms for wireless sensor networks," Computer Communications J., pp. 2826-2841.

[9] Q. Bian., Y. Zhang, and Y. Zhao, 2010. "Research on clustering routing algorithms in wireless sensor networks," in Proc. IEEE Int. Conf. On Intelligent Comput. Technology and Automation, vol. 2, pp. 1110-1113.

[10] P. Zhang, G. Xiao, and H. Tan, 2013. "Clustering algorithms for maximizing the lifetime of wireless sensor networks with energy-harvesting sensors," Comput. Netw. J., pp. 2689-2704. 